Boise State University

ScholarWorks

$5-1-2018$

\title{
Group Characteristics Influence Distribution Patterns of Off-Road Vehicle Recreation within a Complex Trail System in Southwest Idaho
}

Eric Frey

Boise State University

Kathryn Demps

Boise State University

Ben Pauli

Saint Mary's University of Minnesota

Julie A. Heath

Boise State University 
This is an author-produced, peer-reviewed version of this article. The final, definitive version of this document can be found online at Leisure

Sciences, published by Routledge. Copyright restrictions may apply. doi: 10.1080/01490400.2017.1408510

\title{
Group Characteristics Influence Distribution Patterns of Off-Road Vehicle Recreation within a Complex Trail System in Southwest Idaho
}

\author{
Eric Frey \\ Boise State University \\ Katheryn Demps \\ Boise State University \\ Ben Pauli \\ St. Mary’s University of Minnesota \\ Julie A. Heath \\ Boise State University
}

\begin{abstract}
Recreation on public lands is growing and is increasingly recognized as an ecosystem service providing improved health, connection to nature, and social time, while also disturbing and degrading ecosystems. Human impacts must be managed, but often managers have little information about the factors that affect recreation patterns. We combined data from global positioning system receivers to record off-road vehicle (ORV) travel with a pre-trip survey to determine how group characteristics, site experience, site knowledge, and motivation are associated with ORV trip patterns on public lands in southwest Idaho. Spatial and temporal extent and distribution could summarize most variation in ORV trips. Both trip distribution and extent were associated with group characteristics and site knowledge. Spatial and temporal extent was additionally associated with motivations and distribution was associated with riding experience. These findings can help land managers to identify use patterns, direct informational programs, and effect indirect management strategies.
\end{abstract}

\section{Introduction}

Off-road vehicle (ORV) use is a highly valued recreational activity on public lands across the United States (Hallo, Manning, \& Stokowski, 2009), providing participants with a way to experience positive connections with nature, themselves, and others (Lord, Elmerdorf, \& Strauss, 2004; Mann \& Leahy, 2009). During the early 2000s, ORV use in the U.S saw an increase in total participation days of 56\% (Cordell, 2008). It has been predicted that total ORV use could further increase by as much as 58\%, from 48 million participants in 2008 to 76 million by 2060 because of national population increases (Bowker, Askew, Cordell, Betz, Zarnoch, \& Seymore, 2012). Also, technological advances in ORVs, like the introduction of UTVs (utility task vehicles, otherwise known as side-by-sides) increased safety and fuel efficiency, allow a greater number of individuals to participate while also allowing these vehicles to impact greater areas of a landscape (Adams \& McCool, 2009). Unfortunately, ORV use, like other outdoor recreational activities, has been shown to produce negative ecological impacts, including damage to native vegetation and disturbance of wildlife (for extensive reviews on ecological impacts, see Ouren, Haas, Melcher, Stewart, Ponds, Sexton, Burris, Fancher, \& Bowen, 2007; Boyle \& Sampson, 1985). With increases in the amount of recreational use across landscapes, the probability of ecological impacts and human-wildlife conflicts occurring also increases (Duffus \& Dearden, 1990; Leung \& Marion, 2000; Monz, Leung, \& Marion, 2010), placing greater pressures on land managers to not only continue to provide ORV recreationists with opportunities for positive experiences, but also to ensure protection of natural resources. 
This is an author-produced, peer-reviewed version of this article. The final, definitive version of this document can be found online at Leisure Sciences, published by Routledge. Copyright restrictions may apply. doi: 10.1080/01490400.2017.1408510

The challenge of managing public lands for ORV use is often compounded with the absence of data on the ORV recreationists and their use patterns. An integrated approach including social science research is vital to understanding human-impacted ecosystems (Roggenbuck \& Lucas, 1987; Hadwen, Hill, \& Pickering, 2007). This leads to better experiences for recreationists and could support the provision of ecosystem services, while also gaining a better understanding of factors that lead to ecological impacts. However, management decisions are often based solely on data from the environmental and biological realms, limiting the knowledge of how human and ecological systems interact (Grimm, Grove, Pickett, \& Redman, 2000). Spatial and temporal distributions of outdoor recreationists vary and can directly influence ecological impacts (Hadwen et al., 2007; Hallo, Beeco, Goetcheus, McGee, Mcehee, \& Norman, 2012). It has been suggested that social science data on recreationists' characteristics and use patterns must be available and considered to inform accurate environmental decision-making and problem solving by land managers (Watson, 1990; Kessler, Salwasser, Cartwright, \& Caplan, 1992; Wing \& Shelby, 1999; Albritton \& Stein, 2011; D’Antonio, Monz, Newman, Lawson, \& Taff, 2013).

Indirect recreation management strategies intended to influence behavior are generally favored by the public over direct, punitive management schemes (Lucas, 1983; Kuehn, D'Luhosch, Luzadis, Malmsheimer, \& Schuster, 2011). These include signage, published guidelines, and the design of trail systems to encourage recreation behavior compatible with local ecologies. They also tend to cost less to implement, which appeals to land managers and agencies (Manning, 2010). However, managers must first understand which factors contribute to patterns of recreation behavior in order to make indirect management strategies effective (Hendee, Stankey, \& Lucas, 1987). For instance, hikers in Acadia National Park in Maine altered their behavior to reduce impact when approached by a ranger and encouraged to use trails more responsibly, but were not affected by signage above and beyond existing trail markers (Kidd et. al, 2015). Social as well as ecological motivations and ecosystem services matter to recreationists. The gold standard of indirect management would be to provide better recreational opportunities that are compatible with healthy ecosystems (Lucas, 1981).

\section{Human Distributions and Visitor-based GPS Tracking}

Capturing accurate and complete data on recreationist distributions can be a challenge, especially within a complex trail system with multiple trails, routes, and attractions (Hallo et al., 2012; Yang, van Coillie, Liu, De Wulf, Hens, \& $\mathrm{Ou}$, 2014). Written survey methods lack accuracy due to human error such as incomplete recollection and poor spatial awareness (Hallo, Manning, Valliere, \& Budruk, 2005; Isaacson \& Shoval, 2006). Counting equipment, including motion sensor cameras, may provide accurate counts of use at a set point or location, but limits the ability to collect data on movement patterns over an extensive trail system or area (Arrowsmith \& Chhetri, 2003; Cessford \& Muhar, 2003; Yang et al., 2014). Visitor-based GPS tracking of ORV users to collect spatial distributions by providing global positioning system (GPS) receivers to recreationists can be a solution. This method does not rely on human recollection or awareness of the landscape, and provides a complete picture of an individual's movements throughout his/her entire experience. Spatial and temporal data collected by visitor-based GPS tracking can be combined with written survey data on participant characteristics to determine if certain variables (i.e., group characteristics, experience, knowledge, and motivations) affect the travel patterns of the recreating individual or group.

Since the mid-1990s, visitor-based GPS tracking has been used to collect spatial and temporal distributions of humans. One of the earliest studies tracked the movements of elk hunters in Montana (Lyon \& Burcham, 1988). Subsequent researchers have tracked the movements of hikers (D’Antonio, Monz, Lawson, Newman, Pettebone, \& Courtemanch, 2010), boaters (Beeco, Hallo, \& Manning, in press), mountain bikers, and horseback riders (Beeco \& Hallo, 2014). The methodology also has been used in urban settings to analyze transportation patterns (Quiroga \& Bullock, 1998; Murakami \& Wagner, 1999) as well as tourists' movements in urban settings or at public events (Isaacson \& Shoval, 2006; Nielsen \& Stilling Blichfeldt, 2009; Pettersson \& Zillinger, 2011). Utilizing GPS receivers to track human movement patterns and distributions continues to grow in popularity and functionality due to the availability of more precise and less expensive GPS receivers (Hallo et al., 2012). Although the use of visitor-based GPS tracking is a popular method of examining spatial and temporal distributions of recreationists, there is very little previous research available that discusses utilizing these methods to map and analyze ORV distributions. In addition, the majority of visitor-based GPS tracking is used in constrained, limited systems due to the difficulty in retrieval of GPS receivers (Hallo et al., 2012). 
This is an author-produced, peer-reviewed version of this article. The final, definitive version of this document can be found online at Leisure Sciences, published by Routledge. Copyright restrictions may apply. doi: 10.1080/01490400.2017.1408510

\section{$\underline{\text { Recreationist Characteristics and Behavior }}$}

Recreationist behavior varies greatly, even within activity groups. Effective management practices should not be dictated by the preferences and behavior of only one type of user (Manning, 2010). Even within activity type, recreationists vary in the groups in which they choose to recreate (Dottavio, O'Leary, \& Koth, 1980), knowledge of the setting in which they are recreating (Hammitt, Buckland, \& Bixler, 2006), their past experience (Bryan, 1977), and desired benefits from participating (Manfredo, Driver, \& Tarrant, 1996). These differences have been shown to affect how they utilize the landscape across space and time.

For example, the distributions of non-motorized recreationists in a forest setting in South Carolina were affected by the number of individuals within the group (Beeco, 2013). Hikers in Australia were shown to travel more extensively if their planned trip duration was longer (Arrowsmith \& Chhetri, 2003). Skill level has affected site preferences of mountain bikers in North Carolina, with higher skilled riders preferring greater technical and challenging trails more than lower skilled riders (Hopkin \& Moore, 1995). Canoe route choices in a Canadian wilderness area were influenced by past experience and knowledge of the setting, with more experienced or knowledgeable canoeists choosing routes that are more remote and with the least amount of management intervention (McFarlane, Boxall, \& Watson, 1998). Similarly, the desired benefits or motivations of ORV recreationists have been shown to vary, possibly affecting behaviors and setting preferences (Smith \& Burr, 2011). The social dynamics within groups has been theorized to have greater influence on site choice than past experience or setting preferences (Kuentzel \& Heberlein, 1992). These studies suggest that the characteristics of ORV riders may influence individual and group behavior within recreation systems.

Utilizing this past research and theory on recreationists and behavior, we developed a conceptual model (Figure 1) similar to a model put forth by Shoval and Isaacson (2007). Originally conceptualized for the distributions of tourists in a more structured urban environment, the model has been modified previously to examine the distributions of hikers, runners, mountain bikers, and horseback riders within a moderately complex trail system (Beeco \& Hallo, 2014). We hypothesize that the spatial and temporal distributions of ORV recreationists will be associated with the composition of rider groups and members' constraints, site experience, site knowledge, and recreational motivations. Each of these hypothesis categories contains more specific operationalized measurement variables. To our knowledge, our research is the first report that explores factors of ORV recreation distributions.

To evaluate our model, we paired GPS tracking with pre-trip surveys of ORV recreationists within a complex trail system to: 1) Characterize ORV recreationist movement to describe distance, depth, dispersion, and duration of trips; and 2) Determine how riders' group characteristics, site knowledge, site experience, and motivations affected the spatial and temporal pattern of their group's ORV recreation behavior. Our goal was to provide accurate social science data on ORV recreation that can be integrated with existing ecological and biological data for the purpose of more comprehensive management decisions pertaining to ORV recreation.

\section{Methods}

\section{$\underline{\text { Study Area }}$}

We collected data from ORV recreationists in the Murphy Subregion of the Owyhee Front Management Area (OFMA), located in southwest Idaho (USA) (Figure 2). Managed by the Bureau of Land Management (BLM), the subregion is an estimated 94,290 hectares (ha) primarily composed of sagebrush-steppe habitat. A complex network of trails totaling approximately $1350 \mathrm{~km}$ is available for ORV use (U.S. Dept. of the Interior, 2009, 2012). Eight official trailheads with parking areas are available to recreationists for staging and accessing the trail network. A multitude of pull-offs and unofficial parking areas are also used by recreationists to access trails. A "play area" is adjacent to two of the trailheads where riders are not restricted to designated routes and can participate in hill climbing, providing a more unstructured recreation opportunity. The trail system is marked by an alphanumeric system, with signs present at most major intersections. An effort is made by the BLM to maintain signs designating trails as closed, either permanently or seasonally. Most permanently closed trails were accessible prior to the adoption of the Murphy Subregion Travel Management Plan in 2009. In addition, approximately $105 \mathrm{~km}$ of trails are closed seasonally to protect areas deemed as sensitive habitat. Compliance with trail restrictions and closures is not heavily enforced and is primarily left to the discretion of the recreationists. In addition to ORV recreation, the area provides opportunities for other activities including non-motorized recreation, camping, and recreational shooting. 
This is an author-produced, peer-reviewed version of this article. The final, definitive version of this document can be found online at Leisure Sciences, published by Routledge. Copyright restrictions may apply. doi: 10.1080/01490400.2017.1408510

\section{Data Collection}

Data collection occurred from March 13 to May 25, 2015. The majority of sample days were on weekends (Fri - Sun) from late morning to early evening, which coincided with peak use. Participant recruitment by researchers occurred at six of the eight official trailheads. The other two trailheads were not included because of lack of regular use. Typically, we sampled one trailhead each survey day; if multiple researchers were available, multiple trailheads were simultaneously sampled. Efforts were made to approach all observed ORV users - people preparing to ride on a motorized vehicle into the trail system. However, some limitations were experienced because of the concurrent arrival of multiple users at the trailhead. When this happened, we sampled the closest group who appeared to be the most receptive to participating.

Recreationists who chose to participate were given a paper survey. If there was more than one individual in the group, the self-identified most experienced person was asked to complete the survey, in order to estimate the greatest amount of site knowledge and experience within each group, although we encouraged group participation and conversation to formulate answers and minimize potential biased responses from group leaders. The survey requested information pertaining to the individuals of each group as well as the group as a whole. This pre-trip written survey was used to collect demographics and characteristics of each participant and all members in their recreational group. We also asked about travel constraints, knowledge of and experience with the local trail system, and motivations for the trip. The survey contained the following sections (also see Table 1):

\section{Vehicle Type}

Survey takers recorded the vehicle type for each participant in their group. The choices were limited to dirt bike, all-terrain vehicle (ATV), and UTV. A visual check by the researcher was also made once the survey was returned. To account for the differences in trail accessibility, riding groups were reclassified as a binomial variable ( 0 = exclusively 2 -wheel dirt bikes, 1 = at least one four-wheel vehicle).

\section{Group characteristics}

Three distinct group characteristics that could constrain riding behavior were considered for analysis; lowest skill level in group, group size, and the estimated trip duration. The survey taker was asked to assess each group member's skill level pertaining to riding their vehicle. An integer number scale was used with " 1 ” defined as "Beginner" and " 5 ” defined as "Expert”. Beginners may constrain riding behavior for others in the group. Group size was defined as the number of vehicles in each group. Finally, survey takers were asked to answer the question, "How long do you expect to be out today riding?” Answers were converted to minutes.

\section{Site Knowledge}

Knowledge was self-assessed by the survey taker's answer to the question, "How much knowledge do you have of the Owyhee Front area and trail system?” An integer number scale from 1 to 5 was used to record their answer, with an answer of " 1 " defined as "none" and " 5 " defined as "a lot". A second binary variable was also recorded that asked the survey taker "Do you have a plan about where you are going?” to further assess knowledge of the trail system and area.

\section{Site Experience}

The past experience of only the survey taker was measured using both a length and frequency variable. We attempted to recruit the most experienced and knowledgeable participant from each group to fill out the survey. Length of experience was measured by the number of years riding ORVs within the study site and frequency was measured by the number of days riding ORVs within the study site in the previous calendar year.

\section{Motivations}

Three broad motivations were examined that previously had been identified as being important to ORV recreationists (Mann \& Leahy, 2009): a connection with self, a connection with others, and a connection with the natural environment. The measures were either taken directly from the Recreation Experience Preference scale (REP) (Manfredo et al. 1996), or were an amalgam of two similar measures from the REP scale. Two measures were used to assess the motivations of the survey taker only (Table 1). Scores were indicated using a 5-point scale, with $1=$ not important and 5 = very important. 
This is an author-produced, peer-reviewed version of this article. The final, definitive version of this document can be found online at Leisure Sciences, published by Routledge. Copyright restrictions may apply. doi: 10.1080/01490400.2017.1408510

Each group that completed the written survey was given the option of participating in the collection of spatial and temporal data by carrying a GPS tracker. We incentivized participation by offering a data file of their GPS-tracked trip that could be viewed using GoogleEarth or GoogleMaps. If willing, a GPS receiver (Globalsat dg-100) was attached to the individual's vehicle with disposable cinch ties. The Globalsat dg-100 receiver model was previously field tested and found to be an effective unit for tracking recreational use distributions, with a mean precision of 6.7 meters (Hallo et al. 2012). The receiver was turned on several minutes prior to the group leaving the trailhead area to ensure the acquisition of satellite signals. Receivers recorded position, time, date, speed, and altitude on a five-second interval. After the participant returned to the trailhead, we collected the receiver (with a $100 \%$ return rate).

All data collection methods were approved by the Boise State University Institutional Review Board under protocol \#028-SB15-043.

\section{Cleaning and Operationalization of Spatial and Temporal Data}

Each set of points was cleaned using ArcMap 10.2 (ESRI, Redlands, CA, USA). Boundary polygons for each of the six trailhead parking areas were defined to maintain consistency for the beginning and end of each trip. To prevent oversampling of locations before and after the trip, all points except for the final point recorded prior to exiting the trailhead area for the first time were deleted. Likewise, only the first point recorded upon entering the trailhead area for the final time was retained. Each point set was then visually inspected for any position anomalies based on the adjacent points, as well as recorded speeds and time. Any anomalies found were deleted.

For each filtered set of points, three spatial variables (distance, depth, and dispersion) and one temporal variable (duration) were calculated. Distance was defined as the total distance traveled by the participant. Because the receivers continued to record points even while participants were stationary, GPS error during stopping events could artificially inflate distance estimates. Therefore, any point with an associated speed $<0.7 \mathrm{~km} / \mathrm{h}$ was removed. Points were then converted to a line using the points to line tool in ArcMap and total length of the line was then calculated. Depth was defined as the maximum Euclidean distance between the trailhead centroid of the participant's origin and the points within each participant point set. Maximum Euclidean distance was calculated using the point distance analysis tool in ArcMap. Dispersion was defined as the area of the minimum convex polygon (MCP) of all points for each track. MCPs were calculated using the minimum bounding geometry tool for a convex hull in ArcMap. Finally, duration was defined as the elapsed time from the first to the last retained point for each participant.

\section{$\underline{\text { Statistical Analyses }}$}

We used principal component analysis to represent the four distribution variables (distance, depth, dispersion, duration) as multiple orthogonal variables and identify unique dimensions of ORV trips. We used recreation groups as the unit of analysis, because only one vehicle per group carried the GPS receiver. Analysis was done using a correlation matrix because of the different measurement scales of the spatial variables (distance, depth, dispersion) and time variable (duration). Components were retained for analysis based on eigenvalue, percent of variance explained, and examination of the scree plot to identify the dimensions that are most informative in describing ORV distributions.

We assigned predictor variables to four hypothesis categories (group characteristics, site knowledge, site experience, motivations) that represent the factors of interest (Table 1). Within each hypothesis category, we analyzed predictor variables for any significant correlations $(r \geq|0.7|)$. If variables were found to be correlated, only the variable that was the most influential on observed behavior was chosen to be included in each model. We created generalized linear mixed models (GLM) for each hypothesis category to determine the influence of group characteristics, site knowledge, site experience, and motivations on the Principal Component (PC) 1 scores and PC 2 scores of observed ORV trips. We used a two-step model selection method to analyze the influence of each fixed-effect hypothesis category on the distribution components. Models with the lowest $\triangle \mathrm{AICc}$ were considered as the most parsimonious models within each category. We then analyzed best models across hypothesis categories to determine a final model with the best fit. We created models using the R-package "Ime4" (Bates, Maechler, Bolker, \& Walker, 2014). The trailhead sampled, or "location", was considered a random effect variable and was included in all models. The binomial variable "vehicle type" was considered a blocking fixed effect to account for the difference in trail availability between vehicle 
This is an author-produced, peer-reviewed version of this article. The final, definitive version of this document can be found online at Leisure Sciences, published by Routledge. Copyright restrictions may apply. doi: 10.1080/01490400.2017.1408510

types. This variable was included in all models. Parameter estimates for each fixed effect in the final model were reported along with $85 \%$ confidence intervals (Arnold, 2010). Variables with confidence intervals not crossing zero were meaningful for model fit. All analyses were performed in R (R core team 2014).

\section{Results}

A total of 153 ORV recreation groups were asked to participate with 102 (66.7\%) fully participating in both the pretrip written survey and the visitor-employed GPS tracking. Seven groups (6.9\%) returned with incomplete data because of malfunctioning of GPS receivers and we removed their trips from the analysis. The trips from an additional three groups were not used because of missing data from the written survey. One group was determined to be an extreme outlier (more than 1.5 standard deviations from the mean) and was not used in our analysis. This was a very long, deep trip into the trail system that probably reflects a small number of use patterns only captured by this one GPS track. After excluding these, the effective sample size was 91 trips with corresponding written surveys. A total of 191,054 GPS data points were included in the 91 GPS tracks. During cleaning of the data, a total of eight points from three tracks were deleted because of position anomalies. These deleted points did not compromise the accuracy of the distribution data for those three tracks.

\section{Summary of ORV Recreationists}

We collected information on a total of 265 people in 91 groups (Table 2). Most groups had 2-3 people $(\overline{\mathrm{x}}=2.91$, SD $=1.64)$ and $2-3$ vehicles $(\overline{\mathrm{x}}=2.64, \mathrm{SD}=1.57)$. Of the 91 groups, $13(14.3 \%)$ were single individuals.

ORV recreationists in the sampled groups were mostly male (84.2\%) with a mean age of 40 , ranging from 3 to 82 . Of the 41 groups who had more than one rider and complete age information, 22 groups had an age range of 25 years or greater (53.7\%), indicating these groups were comprised of multiple generations of riders.

A majority of participants rode dirt bikes (65.8\%), while $22.9 \%$ utilized ATVs and $11.3 \%$ rode UTVs. Most groups were homogenous being comprised of only one vehicle type, with only 17 of the 91 groups (18.7\%) having two or more different types of vehicle represented. For those individuals who reported their age and were not indicated as passengers, the mean age of dirt bike, ATV, and UTV operators were $37.06(n=96), 47.85(n=39)$, and $47.77(n=$ 22) years, respectively. Six people indicated they would be riding more than one type of vehicle during their trip and were excluded in these means. Using a Kruskal-Wallis test and Dunn's multiple comparison post-hoc test, the age of riders was found to significantly differ by vehicle type ridden $(\mathrm{H}(2)=15.82, \mathrm{p}<0.001)$, with dirt bike riders being significantly younger than both UTV $(p=0.013)$ and ATV operators $(p=0.002)$.

A majority (84 of 91) of survey takers identified their residence as being in the adjacent counties of Ada or Canyon County, Idaho. Of the remaining 7 individuals, four indicated their home zip code as out of state (three in Oregon and one in Colorado).

The mean number of years riding at the study site for the survey respondent was $11.24(\mathrm{SD}=10.74)$ while the mean number of days riding at the study site in the previous calendar year was 13.87 (SD $=21.55)$. Self-assessed site knowledge scores for the survey taker had a mean of 2.99 ( $\mathrm{SD}=1.27$ ), on a scale of 1 (no knowledge) to 5 (complete knowledge). A total of 48 groups (52.75\%) indicated they had a plan about their trip route or destination.

The mean start time for trips was $\sim 12: 30 \mathrm{pm}$. Estimated trip times had a mean of 236 minutes (SD = 99.0). Actual trip durations ranged from 20 to 359 minutes, with a mean of 163 minutes (SD = 76.2). On average, groups overestimated how long they would ride by 73 minutes $(S D=83.1)$. Five groups explained that they ended their trip early because of mechanical issues with one or more vehicles in the group. One group stated that they ended their trip earlier than expected because of inclement weather. The difference in estimated and actual time was still found to be an overestimation of recreation time by 68 minutes $(S D=81.9)$ when these six groups were excluded.

All motivation factors examined were rated at least "important” to the survey takers (Table 2). The motivation with the lowest overall mean, "meet new people", still registered as important (3.2 out of 5). The most important motivation recorded for the total sample was "enjoy the natural environment" (4.8 out of 5). 
This is an author-produced, peer-reviewed version of this article. The final, definitive version of this document can be found online at Leisure Sciences, published by Routledge. Copyright restrictions may apply. doi: 10.1080/01490400.2017.1408510

\section{$\underline{\text { Distribution Variables and PCA }}$}

ORV trip distance, depth, dispersion, and duration (Table 3) were positively correlated with each other (all $\mathrm{r}>0.48$, Table 4). We found sampling adequacy to be 'meritorious' (Kaiser, 1974) for the analysis using the Kaiser-MeyerOlkin $(\mathrm{KMO})$ measure of sampling adequacy $(\mathrm{KMO}=0.8)$, and all $\mathrm{KMO}$ values for individual variables were greater than the suggested minimum acceptable limit of 0.5 (Kaiser, 1974). We found two principle components that describe two different types of trips made by ORV recreationists. The first component (PC1) explained 79\% of the variance and had an eigenvalue of 3.16 while the second component explained $13 \%$ of the variance and had an eigenvalue of 0.54 (Table 5). Although the eigenvalue for PC2 was less than 1, we retained it for analysis because of the steepness of the scree plot and the amount of variance the component explained. The third and fourth components only explained $4 \%$ of the remaining variance and had low eigenvalues of 0.15 . Factor loadings on PC1 for all four distribution variables were negative, indicating that PC1 accounted for variation created by unidirectional changes in distribution, distance, depth, and duration. In other words, high PC1 scores were long trips, with long depth, dispersion, and duration and low PC1 scores were short trips, with short depth, dispersion, and duration (Figure 3). For PC2, depth had a positive loading, duration had a negative loading, and distance and dispersion had relatively low loadings indicating that higher PC2 scores indicated trips with long depth and short duration and low PC2 scores indicated trips with short depth and long duration (Figure 3).

\section{$\underline{\text { Model Selection }}$}

In the assessment of PC1, the best-fit model contained variables from the group characteristics, site knowledge, and motivation hypothesis categories (Table 6). The variables included from a model with only group characteristics were: estimated time, lowest skill, and number of vehicles. In assessing the effect of site knowledge alone on PC1, having a plan was the only important variable. The intercept-only model was found to be the best model when considering only site experience variables. Finally, two motivation variables, meet new people and enjoy nature, were included in a model that best predicted PC1. Using an exploratory approach, the combination of variables from all three hypothesis categories was determined to have the best model fit (Table 6). The group characteristic variables of estimated time $(\beta=-0.0088,85 \% \mathrm{CI}=-0.0080,-0.0069)$ and lowest skill level $(\beta=-0.3184,85 \% \mathrm{CI}=0.1366,-0.1545)$ influenced PC1 negatively; number of vehicles $(\beta=0.2313,85 \% \mathrm{CI}=0.1448,0.3018)$ had a positive effect. Having a plan $(\beta=$ $-0.8408,85 \% \mathrm{CI}=-0.8984,-0.5541)$ and the motivation to enjoy nature $(\beta=-0.2840,85 \% \mathrm{CI}=-0.4438,-0.0291)$ also had negative effects while the motivation to meet new people $(\beta=0.4161,85 \% \mathrm{CI}=0.3634,0.5343)$ influenced PC1 positively in this model.

For PC2, the best-fit model included variables from the group characteristics, site knowledge, and site experience hypothesis categories (Table 7). When only considering variables from group characteristics, the best model included estimated time and number of vehicles per group. Within the knowledge category, we found only the site knowledge variable to be a predictor of travel behavior. Within the site experience category of variables, both experience in years riding and days riding in the last year were present in the best model. The intercept-only model was determined to be the best-performing model relative to those including just the motivation variables - indicating no individual motivation variable was predictive of behavior. When the top models were combined, only constraints and experience contributed to the best final model for PC2 (Table 7). The group constraint variables of estimated time $(\beta=-0.0020$, $85 \% \mathrm{CI}=-0.0035,-0.0012)$ and number of vehicles $(\beta=-0.1693,85 \% \mathrm{CI}=-0.2141,-0.1039)$ each had a negative effect on PC2. The site experience variable, experience in days ( $\beta=-0.0020,85 \%$ CI $=-0.0069,0.0019)$ tended to have a negative influence on PC2 but the CI crossed zero so the effect is unreliable. The variable experience in years $(\beta=0.0175,85 \% \mathrm{CI}=0.0078,0.0252)$ positively influenced $\mathrm{PC} 2$.

\section{Discussion}

Our research shows that ORV recreationist behaviors vary according to group composition, site knowledge, site experience, and motivations of group members for participating. Variables within these hypothesis categories affect the characteristics of their trip within a complex trail system. The best-fit models that explained the two primary types of trip distribution and duration differed in how variables within the hypothesis categories predict travel patterns. We believe our work to be one of the first to explore these influences on distributions for ORV recreation and the first to explore recreation patterns in a large, complex trail system. Combining social and spatial data on recreationist behavior can be a powerful tool for land managers wanting to approximate the drivers behind use patterns on the landscape to increase ecosystem services to users and to design indirect management strategies to minimize impact. 
This is an author-produced, peer-reviewed version of this article. The final, definitive version of this document can be found online at Leisure Sciences, published by Routledge. Copyright restrictions may apply. doi: 10.1080/01490400.2017.1408510

\section{ORV Recreationists and Their Distributions}

Two uncorrelated dimensions described the distributions of ORV recreationists, reflecting two primary recreation patterns in this open, complex trail system. The first dimension, as described by PC1, accounted for the majority of variance (79\%) in trip distributions with all four distribution variables (distance, depth, dispersion, and duration) linked to patterns of recreational travel. This dimension can be interpreted as overall extensiveness of the trip, with low values representing trips that were long in both distance and duration, extending far from the trailhead, and more widely dispersed across the landscape.

Group characteristics, site knowledge, and motivations best predicted this type of ORV trip behavior. An increase in estimated recreation time or skill level within the group (of the most inexperienced person) is positively correlated to the extensiveness of the participant's trip, resulting in longer trips in duration and distance, traveling further from the trailhead, and dispersing more across the landscape. As the perceived length of time available for recreating increases, it seems likely that the group's spatial and actual temporal distributions will also increase. In regards to skill levels within the group, a novice rider may influence the entire group's riding style. It may be necessary for beginners to travel at slower speeds, take more frequent rests, or to remain closer to the trailhead. These results are similar to those found in hikers in Australia (Arrowsmith \& Chhetri, 2003). As we observed with ORV riders, hikers that planned to spend more time recreating with an overnight stay showed an increase in trip distributions. Also, if we consider the presence of children in a group as a surrogate for lowest skill level, groups with children were found to travel less extensively. In our analysis of group size as a constraint, we discovered that as the number of off-road vehicles in a group increases, their trip extent decreases. An increase in the number of vehicles and/or participants could also increase the chance of a mechanical issue or physical injury occurring, forcing the group to return from their trip prematurely, and thus limiting their spatial and temporal distributions. These results support our conceptual model in considering these factors as constraints on the distribution of the recreating group.

Having a plan about the route or destination prior to departing the trailhead had a significant effect on groups' distributions on the landscape, and was associated with longer and more extensive trips. The want and/or need for having a plan may increase for many groups as trips become longer in duration and more extensive due to more complicated logistics and uncertainties. Conversely, the absence of a plan and its negative effects on extensiveness may be exacerbated within a complex trail system such as our study site. The existence of hundreds of different trail segments and intersections may influence where participants of an unplanned trip feel comfortable riding, confining them to an area around the trailhead or easily accessed areas. The existence of a pre-trip plan is not a proxy for site experience, as any first time visitor who researched the trail system on the Internet, or who had access to interpretive maps, can form a trip plan. Consequently, land managers may be able to influence route choice, even with experienced ORV recreationists, by providing more informational and interpretive materials about route and destination choices online or on site. Distributing information to hikers highlighting underused trail routes in Yellowstone National Park was found to significantly increase their use (Krumpe \& Brown, 1982). At our study site, the distribution of information about extensive, underused trails could be used as an indirect management strategy to influence route choice of both experienced and first time visitors, to more evenly distribute use or decrease trail use densities in sensitive habitats.

Two motivational factors, the importance of experiencing the natural environment and the importance of meeting new people, were also significant predictors of trip dimensions. Groups who had a strong desire to experience the natural environment had more extensive distributions while groups who had a greater desire to meet new people had more condensed distributions. This suggests that these two motivations affect the distribution of ORV recreationists in opposing ways, possibly reflecting differing valuations of ecosystem services provided by outdoor recreation. Those with a desire to enjoy the natural environment traveled more extensively, reaching areas of the trail system that are less frequented by other recreationists. These areas, because of lower use levels, may exhibit less aesthetic impacts and may be more sought after by those that prefer experiencing a connection with nature over experiencing a connection with other individuals. Similarly, a study of wilderness hikers that identified 'naturalness' as the highest contributor to overall trip satisfaction showed that human impacts including the widening and extension of trails, litter, and erosion all negatively impacted their trip (Lynn \& Brown, 2003). On the other hand, those groups which had a strong desire to meet new people traveled less extensively and remained in areas closer to the trailhead where use densities are greatest, increasing the chance of meeting others with similar interests. This pattern is supported by a 
This is an author-produced, peer-reviewed version of this article. The final, definitive version of this document can be found online at Leisure Sciences, published by Routledge. Copyright restrictions may apply. doi: 10.1080/01490400.2017.1408510

study of recreationists in Arkansas, which found that individuals seeking a connection with others, or wanting "to be a part of the group", were less sensitive to higher use levels (Ditton Fedler, \& Graefe, 1983). Collecting social data in tandem with spatial use data can identify cultural ecosystem services valued by users and how they impact behavior.

The second dimension of ORV distribution, as described by PC2 representing 13\% of the variation, was characterized by a different type of trip with a negative relationship between depth and duration. One way to interpret this dimension is to characterize those trips with high depth and low duration as 'purpose driven' and trips with low depth and high duration as 'aimless' (Figure 3). Those exhibiting a 'purpose driven' trip dimension may have one destination which they want to visit, or may be traveling far and fast to achieve one goal. ORV users exhibiting an 'aimless' dimension may be viewed as having no set destination or goal, and are simply recreating for the sake of the activity. Two group characteristic variables and two experience variables influence these trip patterns.

An increase in the estimated time or the number of vehicles in the group increases the trip duration and decreases trip depth, making these trips more 'aimless'. This result is somewhat intuitive for the effects of estimated time since duration is the most influential variable in this component. A greater number of vehicles in the group, similar to the first dimension, may increase the chance of vehicle troubles or malfunction which could increase stopping events, thereby increasing duration and decreasing how far into the system the group can travel. Another possible explanation for this influence is the presence of a 'play area' concentrated near two of the most popular trailheads surveyed. These 'play areas' provide a place for unstructured, more aimless riding experiences as opposed to traveling a set trail or visiting a destination. Groups may concentrate their use at these play areas, so that members can customize their own experiences or interact in ways not possible on single-track trails. As for site experience, survey takers who had a greater number of years riding at the site traveled farther into the system in less time than riders with limited or no years of experience. A possible interpretation for this result could be that riders with greater experience know the trail system and landscape better, can travel at faster speeds, and stop less frequently at trail junctions to become oriented or choose a travel route, consequently exhibiting characteristics of a more 'purpose driven' trip.

All hypothesis categories had an influence on ORV distributions to some degree, suggesting that several factors contribute to trip behavior and support our conceptual model (Figure 1). Group characteristics seem to have the greatest influence on motorized spatial and temporal distributions because they influence both trip dimensions. By using the recreation group as our sample as opposed to the individual, we were able to analyze these group dynamics and their effects on ORV distributions. While knowledge and motivations of the group member(s) is associated with the overall extensiveness of the trip, experience is associated with the inverse relationship between a trip's depth and duration. We found that different sets of factors best describe the two uncorrelated trip types, indicating that ORV recreationists are not homogenous, that sub-groups within ORV participants exist, and that these differences can affect how ORV recreationists use the landscape.

An understanding of how each of these factors influences ORV distributions allows land managers to better provide desired recreational opportunities for subsets of ORV users that are compatible with best use practices. This could be accomplished by a number of methods, including selective dissemination of information to certain rider types or highlighting trails or areas that are being underused but highly suitable for a subset of riders. At this site, information tailored toward group size could be provided at trailheads, highlighting longer routes for individuals or small groups and shorter routes for larger groups. Another example may be to highlight underused routes that go deep into the trail system for individuals wanting to experience the natural environment while adding facilities closer to trailheads that might encourage those individuals who have a desire to socialize with and meet other like-minded individuals. Since having a travel plan and knowledge of this complex trail system are associated with depth, duration, and dispersal into the trail system, providing people with the information they need to make a plan can encourage best use practices.

Routes and facilities cannot only be tailored for the recreating group, but also for the health of sensitive species and habitats. Trail, route, and destination recommendations can highlight appealing trails that also diminish impacts on the local ecology. In the large, open, and complex trail systems available in the western United States, visitors can be directed towards areas that decrease impact. Investment by land managers to increase site knowledge of compatible recreation areas and to help people build recreation plans compatible with management objectives. Published routes, guided rides, improved trail signage, and better online trail system resources are all possible indirect management options. 
This is an author-produced, peer-reviewed version of this article. The final, definitive version of this document can be found online at Leisure Sciences, published by Routledge. Copyright restrictions may apply. doi: 10.1080/01490400.2017.1408510

This research, when integrated with biological and ecological knowledge, may help in applying indirect management strategies, thereby making it possible to mitigate resource impacts from recreation activities without regulating ORV access. Compliance with federal regulations may then become more efficient and feasible because of management strategies considering both the ecological impacts of ORV recreation, and the recreationists' uses of the landscape.

\section{Visitor-Based GPS Tracking}

Although visitor-based GPS tracking has been used previously with success for examining other recreation activities, this research is one of the first examples to examine the factors influencing ORV recreationist behavior. We have demonstrated that a written survey paired with visitor-employed GPS tracking is a viable method to analyze social factors that affect spatial and temporal distributions of ORV recreationists. First, the methods for GPS collection and the unit's functionality were shown to be successful. Return rate for GPS receivers was $100 \%$, despite the study being done within a complex trail system with multiple entry and exit points.

Second, using a 5 second time-interval to record data was sufficient to provide an accurate and complete description of distributions and behavior without an overburden of data. Collection intervals should be determined by the scale and purpose of the research, providing sufficient data to identify the behaviors of interest (Beeco \& Hallo, 2014). Longer intervals in this trail system would have provided inaccurate totals of distance traveled because of the speed of ORV travel and the non-linear nature of the trails.

Third, by spatially standardizing the method of start and stop points for each participant, it was possible to eliminate the difficulties of calculating distance traveled and duration of each trip. GPS units needed to be turned on and recording data prior to distributing them to the individual to record accurate positions in the beginning of the participant's trip. Setting the start and stop location spatially by defining boundaries to the trailheads allowed the systematic cleaning of data. The main drawback of this method is the loss of data that describes the behaviors of groups at the trailheads prior to departure and after returning, but this was not of interest for this project.

\section{$\underline{\text { Limitations }}$}

While the application of pairing a pre-trip written survey and visitor-based GPS tracking was successful in analyzing factors of influence on ORV recreation distributions, several limitations were realized. Due to small volume of ORV recreationists at many of the sampled trailheads, a convenience sampling technique was used primarily on weekend days to ensure an adequate sample size. Another sampling size limitation was our method of defining the sampling unit as the recreating group instead of the individual. Although 265 individuals fully participated in the study, our sampling size was 91 groups. This method, however, allowed us to better integrate GPS data with group dynamics of interest such as number of vehicles, skill levels, and whether the group had a plan for their trip. One potential issue with the GPS data is that we did not calibrate the GPS receivers before deploying them. Extreme care was taken in the analysis to identify a standard starting and stopping point to ameliorate this issue. We also were not looking at whether individuals visited specific points in the trail system, but at variables such as absolute distance. With most trips averaging over several kilometers, calibrating within a few feet most likely introduced minimal measurement error. Another limitation was the use of self-assessments for certain rider characteristics such as site knowledge and skill level. A broader set of questions may have produced more informative values for these variables, but would have increased the amount of time needed to complete the survey and possibly reduce our participation rate. Finally, because of ethics and protocols of human studies, participant's awareness that their movements were being recorded may have biased riding behavior or participation. Individuals planning to ride off-trail or in ways they felt might be punished, if discovered, may have been more likely to decline to carry a GPS device, thus biasing our sample towards individuals following perceived good behavior.

\section{Conclusion}

We have provided a case study that exhibits the functionality of a written survey and visitor-based GPS tracking to analyze factors of ORV use distributions. Distribution data standing alone has the ability to identify uneven use distributions, informing managers how to best mitigate resource impacts and perceptions of crowding, as well as promoting areas that are underutilized by ORV recreationists. When integrated with user characteristics, managers can understand the underlying patterns of distribution differences and implement indirect strategies that influence human behavior and patterns consistent with sustainable use, as opposed to regulating users. 
This is an author-produced, peer-reviewed version of this article. The final, definitive version of this document can be found online at Leisure Sciences, published by Routledge. Copyright restrictions may apply. doi: 10.1080/01490400.2017.1408510

\section{References}

Adams, J. C., \& McCool, S. F. (2009). Finite recreation opportunities: The Forest Service, the Bureau of Land Management, and off-road vehicle management. Natural Resources Journal, 49, 45.

Albritton, R., \& Stein, T. V. (2011). Integrating social and natural resource information to improve planning for motorized recreation. Applied Geography, 31(1), 85-97.

Arnold, T. W. (2010). Uninformative parameters and model selection using Akaike's Information Criterion. The Journal of Wildlife Management, 74(6), 1175-1178.

Arrowsmith, C., \& Chhetri, P. (2003). Port Campbell National Park: Patterns of Use. A report handed to parks Victoria visitor research, June.

Bates, D., Maechler, M., Bolker, B., \& Walker, S. (2014). lme4: Linear mixed-effects models using Eigen and S4. R package version 1.1-7. This is computer program (R package). The URL of the package is: http://CRAN. Rproject. org/package $=$ Ime4.

Beeco, J. A., Hallo, J. C., \& Manning, R. (in press). GPS as a method for tracking visitors in natural environments. In J. M. Baas \& R. Burns (Eds.), Best Practices in Recreation Resource Planning: A Resource Guide for Planners: Chapter 6. Using GIS Applications. State College, PA: Venture Publishing.

Beeco, J. (2013). Integrating spatial modeling into recreational planning in parks and protected areas (Doctoral dissertation). Retrieved from Clemson University Tiger Prints.

Beeco, J. A., \& Hallo, J. C. (2014). GPS tracking of visitor use: factors influencing visitor spatial behavior on a complex trail system. Journal of Park and Recreation Administration, 32(2), 43-61.

Bowker, J. M., Askew, A. E., Cordell, H. K., Betz, C. J., Zarnoch, S. J., \& Seymour, L. (2012). Outdoor recreation participation in the United States-projections to 2060: a technical document supporting the Forest Service 2010 RPA Assessment. General Technical Report-Southern Research Station, USDA Forest Service (SRS$160)$.

Bryan, H. (1977). Leisure value systems and recreational specialization: The case of trout fishermen. Journal of leisure research, 9(3), 174.

Cessford, G., \& Muhar, A. (2003). Monitoring options for visitor numbers in national parks and natural areas. Journal for nature conservation, 11(4), 240-250.

Cordell, H. K. (2008). Off-highway vehicle recreation in the United States and its regions and states: a national report from the National Survey on Recreation and the Environment (NSRE). Southern Research Station.

D’Antonio, A., Monz, C., Lawson, S., Newman, P., Pettebone, D., \& Courtemanch, A. (2010). GPS-based measurements of backcountry visitors in parks and protected areas: examples of methods and applications from three case studies. Journal of Park and Recreation Administration, 28(3).

D’Antonio, A., Monz, C., Newman, P., Lawson, S., \& Taff, D. (2013). Enhancing the utility of visitor impact assessment in parks and protected areas: A combined social-ecological approach. Journal of environmental management, 124, 72-81.

Ditton, R. B., Fedler, A. J., \& Graefe, A. J. (1983). Factors contributing to perceptions of recreational crowding. Leisure Sciences, 5(4), 273-288.

Dottavio, F. D., O’Leary, J. T., \& Koth, B. A. (1980). The social group variable in recreation participation studies. Journal of Leisure Research, 12(4), 357.

Duffus, D. A., \& Dearden, P. (1990). Non-consumptive wildlife-oriented recreation: A conceptual framework. Biological Conservation, 53(3), 213-231.

Exec. Order 11644. (1972). Page 666 CFR.

Grimm, N. B., Grove, J. G., Pickett, S. T., \& Redman, C. L. (2000). Integrated Approaches to Long-Term Studies of Urban Ecological Systems Urban ecological systems present multiple challenges to ecologists-pervasive human impact and extreme heterogeneity of cities, and the need to integrate social and ecological approaches, concepts, and theory. BioScience, 50(7), 571-584.

Hadwen, W. L., Hill, W., \& Pickering, C. M. (2007). Icons under threat: Why monitoring visitors and their ecological impacts in protected areas matters. Ecological Management \& Restoration, 8(3), 177-181.

Hallo, J. C., Beeco, J. A., Goetcheus, C., McGee, C., McGehee, N. G., \& Norman, W.C. (2012). GPS as a method for assessing spatial and temporal use distributions of nature-based tourists. Journal of Travel Research, 51(5), 591-606.

Hallo, J. C., Manning, R. E., \& Stokowski, P. A. (2009). Understanding and managing the off-road vehicle experience: indicators of quality. Managing Leisure, 14(3), 195-209. 
This is an author-produced, peer-reviewed version of this article. The final, definitive version of this document can be found online at Leisure Sciences, published by Routledge. Copyright restrictions may apply. doi: 10.1080/01490400.2017.1408510

Hallo, J. C., Manning, R. E., Valliere, W., \& Budruk, M. (2005). A case study comparison of visitor self-reported travel routes and GPS recorded travel routes. Proceedings of the 2004 Northeastern Recreation Research Symposium.

Hammitt, W. E., Backlund, E. A., \& Bixler, R. D. (2006). Place bonding for recreation places: Conceptual and empirical development. Leisure Studies, 25(1), 17-41.

Hendee, J. C., G. H. Stankey, and R. C. Lucas. 1978. Wilderness Management. Forest Service, US Department of Agriculture.

Hopkin, T. E., \& Moore, R. L. (1995). The relationship of recreation specialization to the setting preferences of mountain bicyclists, 71-75. General Technical Report, Saratoga Springs, NY.

Isaacson, M., \& Shoval, N. (2006). Application of Tracking Technologies to the Study of Pedestrian Spatial Behavior. The Professional Geographer, 58(2), 172-183.

Issa, B. (2003). Development of Guidance and Evaluation Criteria for Off-Highway Vehicle (ORV) Management Planning. Department of Planning, Public Policy \& Management, University of Oregon.

Kaiser, H. F. (1974). An index of factorial simplicity. Psychometrika, 39(1), 31-36.

Kessler, W. B., Salwasser, H. , Cartwright Jr, C. W., \& Caplan, J. A. (1992). New perspectives for sustainable natural resources management. Ecological Applications, 2(3), 221-225.

Krumpe, E. E., \& Brown, P. J. (1982). Using information to disperse wilderness hikers. Journal of Forestry, 79, 9292.

Kuehn, D. M., D’Luhosch, P. D., Luzadis, V. A., Malmsheimer, R. W., \& Schuster, R. M. (2011). Attitudes and intentions of off-highway vehicle riders toward trail use: Implications for forest managers. Journal of Forestry, 109(5), 281-287.

Kuentzel, W. F., \& Heberlein, T. A. (1992). Does specialization affect behavioral choices and quality judgments among hunters? Leisure Sciences 14(3), 211-226.

Leung, Y.F., \& Marion, J. L. (2000). Recreation impacts and management in wilderness: A state-of-knowledge review, 23-48. Wilderness science in a time of change conference.

Lord, B. E., Elmerdorf, W. F., \& Strauss, C H. (2004). Pennsylvania's ATV riders and their needs. Project report to: PA Department of Conservation and Natural Resources.

Lucas, R. C. (1981). Redistributing wilderness use through information supplied to visitors. USDA Forest Service Research Paper, Intermountain Forest and Range Experiment Station, Forest Service, US Department of Agriculture (INT-277).

Lucas, R. C. (1983). The role of regulations in recreation management. Western Wildlands, 9(2), 6-10.

Lynn, N. A., \& Brown, R. D. (2003). Effects of recreational use impacts on hiking experiences in natural areas. Landscape and Urban Planning, 64(1), 77-87.

Lyon, L. J., \& Burcham, M. G. (1988). Tracking Elk Hunters with theGlobal Positioning System. US Department of Agriculture, Forest Service, Rocky Mountain Research Station, Fort Collins, Colorado, USA.

Manfredo, M. J., Driver, B. L., Tarrant, M. A. (1996). Measuring leisure motivation: A meta-analysis of the recreation experience preference scales. Journal of Leisure Research, 28(3), 188.

Manning, R. E. (2010). Studies in Outdoor Recreation: Search and Research for Satisfaction. Oregon State University Press, Corvallis.

Mann, M. J., \& Leahy, J. E. (2009). Connections: Integrated meanings of ATV riding among club members in Maine. Leisure Sciences, 31(4), 384-396.

McFarlane, B. L., Boxall, P. C., \& Watson, D. O. (1998). Past experience and behavioral choice among wilderness users. Journal of Leisure Research, 30, 195-213.

Monz, C. A., Cole, D. N., Leung, Y. F., \& Marion, J. L. (2010). Sustaining visitor use in protected areas: future opportunities in recreation ecology research based on the USA experience. Environmental Management, 45(3), 551-562.

Murakami, E., \& Wagner, D. P. (1999). Can using global positioning system (GPS) improve trip reporting? Transportation research part c: emerging technologies, 7(2),149-165.

Nielsen, N. C., \& Stilling Blichfeldt, B. (2009). Where do they go? Monitoring tourist mobility at the destination. 18th Nordic Symposium in Tourism and Hospitality Research.

Ouren, D., Haas, C., Melcher, C., Stewart, S., Ponds, P., Sexton, N., Burris, L., Fancher, T., \& Bowen, Z. (2007). Environmental effects of off-highway vehicles on Bureau of Land Management lands: A literature synthesis, annotated bibliographies, extensive bibliographies, and internet resources. US Geological Survey, Open-File Report, 1353, 225.

Pettersson, R., \& Zillinger, M. (2011). Time and space in event behaviour: tracking visitors by GPS. Tourism Geographies, 13(1), 1-20. 
This is an author-produced, peer-reviewed version of this article. The final, definitive version of this document can be found online at Leisure Sciences, published by Routledge. Copyright restrictions may apply. doi: 10.1080/01490400.2017.1408510

Quiroga, C. A., \& Bullock, D. (1998). Travel time studies with global positioning and geographic information systems: an integrated methodology. Transportation Research Part C: Emerging Technologies, 6(1), 101127.

R Core Team. 2014. R: a language and environment for statistical computing. R Foundation for Statistical Computing, Vienna, Austria: http://www.R-project.org/.

Roggenbuck, J. W., \& Lucas, R.C. (1987). Wilderness use and user characteristics. A state-of-knowledge review. General Technical Report, Intermountain Research Station, USDA Forest Service, (INT-220), 204-245.

Sheridan, D. (1979). Off-road vehicles on public land. Off-road vehicles on public land.

Shoval, N., Isaacson, M. (2007). Tracking tourists in the digital age. Annals of Tourism Research, 34(1), 141-159.

Smith, J., \& Burr, S. (2011). Environmental attitudes and desired social-psychological benefits of off-highway vehicle users. Forests, 2(4), 875-893.

U.S. Department of the Interior, Bureau of Land Management, Murphy Subregion travel management plan. Environmental Assessment. 2009. ID-130-2007-EA-3431.

$<$ http://www.blm.gov/pgdata/etc/medialib/blm/id/travel_management/murphy_travel_management.Par.758 63.File.dat/Murphy_Subregion_TMP_ID-130-2007-EA-3431_2.pdf>. Accessed 12 November 2014.

U.S. Department of the Interior, Bureau of Land Management, Travel Management Program, 2012.<http://www.blm.gov/wo/st/en/prog/Recreation/recreation_national/travel_management.print.html.> Accessed 12 November 2014.Watson, A. E. 1990. Why is it important to monitor social conditions in wilderness?

Wing, M., \& Shelby, B. (1999). Using GIS to integrate information on forest recreation. Journal of Forestry, 97(1), 12-16.

Yang, M., van Coillie, F., Liu, M., De Wulf, R., Hens, L., \& Ou, X. (2014). A GIS Approach to Estimating Tourists' Off-road Use in a Mountainous Protected Area of Northwest Yunnan, China. Mountain Research and Development, 34(2), 107-117. 
This is an author-produced, peer-reviewed version of this article. The final, definitive version of this document can be found online at Leisure Sciences, published by Routledge. Copyright restrictions may apply. doi: 10.1080/01490400.2017.1408510

Table 1. Group characteristics, site experience, site knowledge, and motivation variables evaluated as potential factors of ORV recreationist distributions. A random effect (location) and a blocked effect (vehicle type) were included in all models.

\begin{tabular}{|c|c|c|}
\hline Model Category & Variable & Description \\
\hline \multirow[t]{3}{*}{ Group characteristics } & Estimated time & Estimated duration of the participant's trip (minutes) \\
\hline & Number of vehicles & Number of vehicles in participant group \\
\hline & Lowest skill level & Lowest self-assessed skill level of any ORV operator in group [1, Beginner : 5, Expert] \\
\hline \multirow[t]{2}{*}{ Site Experience } & Experience in years & Number of years ORV recreating at study site by survey taker \\
\hline & Experience in days & Number of days ORV recreating at study site in previous year by survey taker \\
\hline \multirow[t]{2}{*}{ Site Knowledge } & Site knowledge & Self-assessed score of the survey taker's knowledge of site and trail system [1, none : 5 , a lot] \\
\hline & Plan & $0=$ No plan about their trip/destination; 1 = Have a plan about their trip/destination \\
\hline \multirow[t]{6}{*}{ Motivations } & Meet new people & $1-5$ self-assessed score about importance of meeting new people who enjoy similar things \\
\hline & Share time with others & $1-5$ self-assessed score about importance of sharing time with friends and/or family \\
\hline & Experience solitude & 1 - 5 self-assessed score about importance of experiencing solitude or "getting away from it all" \\
\hline & Challenge & $1-5$ self-assessed score about importance of challenging oneself or developing their skills \\
\hline & Enjoy nature & 1 - 5 self-assessed score about importance of enjoying the natural environment \\
\hline & View wildlife & $1-5$ self-assessed score about importance of enjoying/viewing wildlife \\
\hline Random Effect & Location & Trailhead where participant’s trip began and ended \\
\hline Blocked Effect & Vehicle type & $0=$ Only dirt bikes in group; $1=$ One or more quad vehicle in group \\
\hline
\end{tabular}


This is an author-produced, peer-reviewed version of this article. The final, definitive version of this document can be found online at Leisure Sciences, published by Routledge. Copyright restrictions may apply. doi: 10.1080/01490400.2017.1408510

Table 2. Description of recreationist population $(\mathrm{n}=91)^{1}$

\begin{tabular}{|c|c|c|c|c|}
\hline & Variable & Range & Mean & SD \\
\hline \multirow{3}{*}{$\begin{array}{l}\text { Group } \\
\text { characteristics }\end{array}$} & Estimated time (min) & $90-480$ & 236.20 & 99.02 \\
\hline & Number of vehicles & $1-9$ & 2.64 & 1.57 \\
\hline & Lowest skill level & $1-5$ & 2.71 & 1.23 \\
\hline \multirow[t]{2}{*}{ Site Experience } & Experience in years & $0-40$ & 11.24 & 10.74 \\
\hline & Experience in days & $0-150$ & 13.87 & 21.55 \\
\hline \multirow[t]{2}{*}{ Site Knowledge } & Site knowledge & $1-5$ & 2.99 & 1.27 \\
\hline & Plan & $0-1$ & \multicolumn{2}{|c|}{$\begin{array}{l}52.75 \% \text { of groups } \\
\text { indicated they had a } \\
\text { pre-trip plan }\end{array}$} \\
\hline \multirow[t]{6}{*}{ Motivations } & Meet new people & $1-5$ & 3.20 & 1.17 \\
\hline & Share time with others & $1-5$ & 4.63 & 0.81 \\
\hline & Challenge & $2-5$ & 4.23 & 0.79 \\
\hline & Experience solitude & $3-5$ & 4.52 & 0.72 \\
\hline & Enjoy nature & $3-5$ & 4.76 & 0.50 \\
\hline & View wildlife & $2-5$ & 4.54 & 0.76 \\
\hline
\end{tabular}

Table 3. Description of ORV trips $(n=91)$ measured by GPS surveys.

\begin{tabular}{lllll}
\hline Variable & Unit & Range & Mean & SD \\
\hline Distance & $\mathrm{km}$ & $7.34-106.89$ & 43.60 & 20.62 \\
Depth & $\mathrm{km}$ & $1.78-32.28$ & 10.92 & 6.56 \\
Dispersion & $\mathrm{km}^{2}$ & $0.98-205.02$ & 39.64 & 39.21 \\
Duration & $\mathrm{min}$ & $20-359$ & 163.00 & 76.21 \\
\hline
\end{tabular}

\footnotetext{
${ }^{1}$ Lowest skill level and knowledge variables based on a 1 to 5 integer scale $(1=$ none, $5=$ a lot $)$. Motivation category variables based on a 1 to 5 integer scale ( 1 = not important, 5 = very important $)$.
} 
This is an author-produced, peer-reviewed version of this article. The final, definitive version of this document can be found online at Leisure Sciences, published by Routledge. Copyright restrictions may apply. doi: 10.1080/01490400.2017.1408510

Table 5. Summary of principal component analysis results of distribution variables $(\mathbf{n}=91) .{ }^{2}$

\begin{tabular}{lll}
\hline & PC1 & PC2 \\
\hline Distance & $\mathbf{- 0 . 5 3 1}$ & 0.013 \\
Depth & $\mathbf{- 0 . 5 1 1}$ & $\mathbf{0 . 4 0 2}$ \\
Dispersion & $\mathbf{- 0 . 5 1 9}$ & 0.310 \\
Duration & $\mathbf{- 0 . 4 3 3}$ & $\mathbf{- 0 . 8 6 1}$ \\
\hline Eigenvalue & 3.163 & 0.535 \\
\% variance & 79.08 & 13.38 \\
\hline
\end{tabular}

Table 6. AICc table of candidate models assessing the influence of individual and group characteristics on PC1 of ORV distributions. Models represent the best combination of variables within each model category, listed in order of strongest to weakest. ${ }^{3}$

\begin{tabular}{llll}
\hline Model $^{1}$ & $\boldsymbol{K}$ & $\boldsymbol{\Delta A I C c}$ & $\boldsymbol{w}_{\boldsymbol{i}}$ \\
\hline Constraints $^{2}+$ Knowledge $^{3}+$ Motivations $^{4}$ & 10 & 0.00 & 0.79 \\
Constraints + Knowledge & 8 & 3.69 & 0.12 \\
Constraints + Motivations & 9 & 4.65 & 0.08 \\
Constraints & 7 & 9.04 & 0.01 \\
Knowledge + Motivations & 7 & 20.89 & 0.00 \\
Knowledge & 6 & 23.86 & 0.00 \\
Motivations & 6 & 24.46 & 0.00 \\
Intercept-only & 4 & 26.46 & 0.00 \\
\hline
\end{tabular}

${ }^{1}$ All models included the random effect variable Location and the blocked effect variable Vehicle Type

${ }^{2}$ Constraints $=$ Estimated Time + Lowest Skill Level + Number of Vehicles

${ }^{3}$ Knowledge $=$ Plan

${ }^{4}$ Motivations $=$ Meet New People + Enjoy Nature

\footnotetext{
${ }^{2}$ Loadings $>0.4$ are in bold.

${ }^{3} \mathrm{~K}=$ number of free parameters in the model, $\Delta \mathrm{AICc}=$ relative quality of the model with 0 being highest, $w_{i}=$ relative likelihood of the model representing the truth.
} 
This is an author-produced, peer-reviewed version of this article. The final, definitive version of this document can be found online at Leisure Sciences, published by Routledge. Copyright restrictions may apply. doi: 10.1080/01490400.2017.1408510

Table 7. AICc table of candidate models assessing the influence of individual and group characteristics on PC2 of ORV distributions. Models represent the best combination of variables within each model category. ${ }^{4}$

\begin{tabular}{llcc}
\hline Model $^{1}$ & $\boldsymbol{K}$ & $\boldsymbol{\Delta A I C c}$ & $\boldsymbol{w}_{\boldsymbol{i}}$ \\
\hline Constraints $^{2}+$ Experience $^{3}$ & 8 & 0.00 & 0.50 \\
Constraints + Experience + Knowledge $^{4}$ & 9 & 1.17 & 0.28 \\
Constraints + Knowledge & 7 & 1.64 & 0.22 \\
Experience + Knowledge & 7 & 23.80 & 0.00 \\
Intercept-only & 4 & 26.31 & 0.00 \\
\hline
\end{tabular}

${ }^{1}$ All models included the random effect variable Location and block variable Vehicle Type

${ }^{2}$ Constraints $=$ Estimated Time + Number of Vehicles

${ }^{3}$ Experience $=$ Experience in Years + Experience in Days

${ }^{4}$ Knowledge $=$ Site Knowledge

${ }^{4} \mathrm{~K}=$ number of free parameters in the model, $\Delta \mathrm{AICc}=$ relative quality of the model with 0 being highest, $w_{i}=$ relative likelihood of the model representing the truth. 